Article 186

Received: October 29, 2021

Accepted: November 13, 2021
Journal of Electrical Engineering and Information Technologies, Vol. 6, No. 2, pp. 67-77 (2021)

In print: ISSN $2545-4250$

On line: ISSN 2545-4269

UDC: $621.395 .721 .5-028.33: 004.722 .4 .02$

https://doi.org/10.51466/JEEIT2162186067s

Original scientific paper

\title{
6G MOBILE NETWORKS: RESEARCH TRENDS, CHALLENGES AND POTENTIAL SOLUTIONS
}

\author{
Stojan Kitanov ${ }^{1}$, Ivan Petrov ${ }^{2}$, Toni Janevski ${ }^{3}$ \\ ${ }^{1}$ Faculty of Informatics, Mother Teresa University, \\ Mirče Acev 4, 1000 Skopje, Republic of North Macedonia \\ ${ }^{2}$ Business Operations Unit, Makedonski Telekom A.D. Skopje, \\ Kej 13 Noemvri 6, 1000 Skopje, Republic of North Macedonia \\ ${ }^{3}$ Faculty of Electrical Engineering and Information Technologies, \\ "Ss. Cyril and Methodius" University in Skopje, Republic of North Macedonia \\ stojan.kitanov@unt.edu.mk // ivan.petrov@telekom.mk // tonij@ feit.ukim.edu.mk
}

\begin{abstract}
A b s t r a c t: Since the standardization of 5G mobile networks has been completed, the deployments of 5G network has started all over the world. 5G mobile and wireless networks have achieved significant improvements in terms of latency, data rates, spectral efficiency, mobility and number of connected smart mobile devices. Therefore, they have marked the beginning of a true digital society. Although 5G network offers support of many broadband applications and services, still it may not be able to meet the rapid increase of the traffic demands. Therefore, the main research and development activities started to focus on the next $6 \mathrm{G}$ mobile and wireless network, which is expected to be commercially available around 2030. In this direction, this paper highlights the vision of the technologies used in 6G network, $6 \mathrm{G}$ network architecture, $6 \mathrm{G}$ network challenges and potential solutions.
\end{abstract}

Key words; 5G; 6G; Artificial Intelligence (AI); Internet of Things (IoT); mobile networks; mobile technology

\section{МОБИЛНИ 6G МРЕЖИ: НАСОКИ НА ИСТРАЖУВАЊЕ, ПРЕДИЗВИЦИ И МОЖНИ РЕШЕНИЈА}

\begin{abstract}
А п с т р а к т: Бидејќ́ процесот на стандардизацијата на мобилните 5G мрежи е веќе завршен, започната е имплементацијата на мрежата 5G низ целиот свет. Мобилните и безжични мрежи 5G имаат значителни подобрувања во поглед на латентноста, податочните брзини, спектралната ефикасност, мобилноста и бројот на поврзани уреди. Затоа тие го имаат означено почетокот на вистинско дигитално општество. Иако 5G-мрежата нуди поддршка на голем број апликации и сервиси, сепак нема да биде во можност да ги задоволи барањата на рапидно зголемените сообраќајни побарувања. Затоа главните истражувачки и развојни активности почнаа да се фокусираат на идните мобилни и безжични мрежи 6G за кои се очекува да бидат комерцијално достапни околу 2030 година. Во таа насока, овој труд ја истакнува визијата на технологиите што ќе се користат во мобилните 6G мрежи, 6G-мрежната архитектура, предизвиците на 6G-мрежите, како и потенцијалните решенија.
\end{abstract}

Клучни зборови: 5G; 6G; вештачка интелигенција (AI); интернет на нештата (IoT); мобилни мрежи; мобилна технологија

\section{INTRODUCTION}

5G mobile and wireless networks achieve significant improvements in terms of latency, data rates, spectral efficiency, mobility and number of connected smart mobile devices. Therefore, they have marked the beginning of a true digital society.
Nowadays there is a shift towards a society of fully automated and remote management systems in number of business sectors and industries. The rapid development of artificial intelligence (AI), virtual reality, three-dimensional (3D) media, and the internet of everything (IoE), has led to a massive volume 
of traffic [1]. The global mobile traffic in 2030 is predicted to be around $5000 \mathrm{~EB} /$ month [2].

Although 5G network offers support of many broadband applications and services, still it may not be able to meet the rapid increase of the traffic demands [3]. In particular, the holographic communication may require a data rate up to terabits per second $(\mathrm{Tb} / \mathrm{s})$, that is almost three times higher than the $5 \mathrm{G}$ 's data rate and massive low latency (hundreds of microseconds), which is three time less than 5G's latency [4-6]. Moreover, as a result of the everincreasing growth of the deployment of Internet of Things (IoT) and future Internet of Everything (IoE) devices, it would be necessary to improve further the connection density and coverage of $5 \mathrm{G}$ enabled IoT networks [7 -8]. In addition, the future mobile networks are expected to be ultra-large-scale, highly dynamic, and incredibly complex system. Therefore, the manual optimization and configuration tasks used in the existing mobile networks would be no longer suitable for the next generation mobile networks [9-12]. At last, the new emerging services of Internet of Everything (IoE) such as extended reality (XR), telemedicine systems, mindmachine interface (MMI), and flying cars would demand high transmission rates, high reliability, and low latency, which significantly exceeds the original goals of the 5G networks [13-15].

Therefore, with the beginning of global deployment as well as global commercialization of $5 \mathrm{G}$ mobile network, the $6 \mathrm{G}$ network research initiatives have gained significant attention in both academy and industry.

$6 \mathrm{G}$ mobile and wireless networks would provide a large coverage that allows subscribers to communicate with one another everywhere with a high data rate speed due to the unconventional technologies such as extremely large bandwidth due to the $\mathrm{THz}$ waves, and the artificial intelligence. AI will be the driving force in designing and optimizing 6G architectures, protocols, and operations. These networks would drastically re-shape the wireless evolution from "connected things" to "connected intelligence" [16]. In particular, 6G would provide support of ubiquitous and mobiquitous AI services from the core to the end devices of the network, which would exceed the mobile internet used today.

At the moment the initiatives of $6 \mathrm{G}$ primarily focus on identifying the main drivers, performance requirements, and technological innovations related to $6 \mathrm{G}$.
In this direction, this paper highlights the vision of the technologies used in $6 \mathrm{G}$ network, $6 \mathrm{G}$ network architecture, $6 \mathrm{G}$ network challenges and potential solutions. The rest of the paper is organized as follows. Section 2 explains the roadmap of $6 \mathrm{G}$ network. Section 3 provides details about $6 \mathrm{G}$ network requirements. The $6 \mathrm{G}$ use cases are elaborated in Section 4. Section 5 describes the $6 \mathrm{G}$ service classes. Section 6 provides details about the possible $6 \mathrm{G}$ network architecture. Section 7 compares the user throughput between $5 \mathrm{G}$ and $6 \mathrm{G}$ network. Finally, Section 8 concludes the paper, addresses the challenges in $6 \mathrm{G}$ network that need to be resolved and provides directions for future work.

\section{THE ROADMAP OF 6G NETWORK}

Different standard organizations and bodies have proposed different roadmaps to $6 \mathrm{G}$ network [16]. The roadmap of $6 \mathrm{G}$ network envisioned by different organization standards, such as 3GPP, ITU, and $\mathrm{PoC}$, is presented in Figure 1. It can be noticed that the current phase is the vision of $6 \mathrm{G}$ network. The next phase that includes study and definition of the $6 \mathrm{G}$ network requirements, as well as development of $6 \mathrm{G}$ network components would start around 2022. The definitions of specification and standards of $6 \mathrm{G}$ network are expected to start around 2025. The evaluation and the testbeds of $6 \mathrm{G}$ network would start around 2026. Finally, the first $6 \mathrm{G}$ commercially deployed network would be around 2030 .

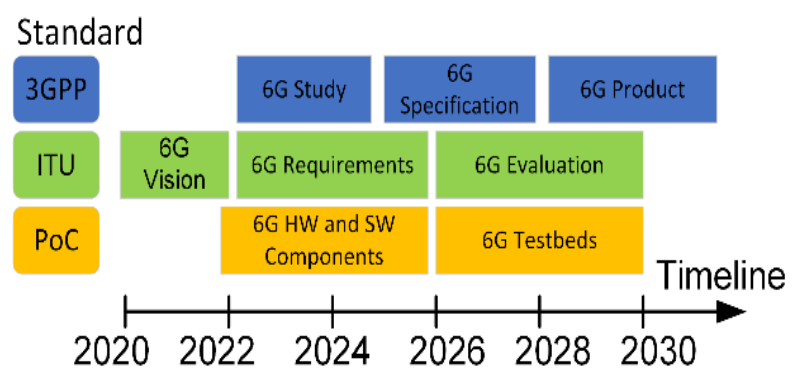

Fig. 1. The roadmap of $6 \mathrm{G}$ network

\section{6G NETWORK REQUIREMENTS}

In order to address the issues that current $5 \mathrm{G}$ network is facing, new strategies such as operation in shared spectrum bands, inter-operator spectrum sharing, heterogeneous networks, leasing networking slices on-domain should be considered. Therefore, $6 \mathrm{G}$ network should satisfy new requirements. 
A comparison of the requirements between $5 \mathrm{G}$ and $6 \mathrm{G}$ network are given in Table 1 [17]. It can be noticed that all parameters such as traffic capacity, data rate, end-to-end delay, processing delay, spectral and energy efficiency etc., are improved several times over the value provided by $5 \mathrm{G}$. New service classes would be introduced in 6G. The service classes would be discussed in Section 4.

In addition, $6 \mathrm{G}$ network should require higher frequency bands in the terahertz spectrum, i.e., millimeter waves. In addition, a very high and opportunistic data rate is required to support new emerging applications, such as immersive multimedia [18]. Also, 6G network would require much end-toend delay of less than 1 millisecond, in order to support some $6 \mathrm{G}$ services such as augmented reality, and telepresence. Furthermore, $6 \mathrm{G}$ network must require too high reliability, in order to enable mission and safety-critical applications.

Table 1

$5 G$ vs $6 G$ requirements

\begin{tabular}{|c|c|c|}
\hline- & $5 \mathrm{G}$ & $6 \mathrm{G}$ \\
\hline Latency & $1 \mathrm{~ms}$ & $0.1 \mathrm{~ms}$ \\
\hline Traffic capacity & $10 \mathrm{Mbps} / \mathrm{m}^{2}$ & $10 \mathrm{Gbps} / \mathrm{m}^{3}$ \\
\hline Latency & Fair & Slightly annoying \\
\hline $\begin{array}{l}\text { Localization pre- } \\
\text { cision }\end{array}$ & $10 \mathrm{~cm}$ on $2 \mathrm{D}$ & $1 \mathrm{~cm}$ on $3 \mathrm{D}$ \\
\hline User experience & $\begin{array}{l}50 \text { Mbps 2D every- } \\
\text { where }\end{array}$ & $\begin{array}{l}10 \text { Gbps 3D every- } \\
\text { where }\end{array}$ \\
\hline DL peak rate & $100 \mathrm{Gbps}$ & $1 \mathrm{Tbps}$ \\
\hline UL peak rate & $50 \mathrm{Gbps}$ & $\sim 1$ Tbps \\
\hline Reliability & FER $10^{-5}$ & FER $10^{-9}$ \\
\hline Service classes & $\begin{array}{l}\text { eMBB, URLLC, } \\
\text { mMTC }\end{array}$ & $\begin{array}{l}\text { mURLLC, eURLLC, } \\
\text { meMBB, COC, } \\
\text { EDuRLLC, CAeC, } \\
\text { uHSLLC, uHDD, } \\
\text { uMUB HCS, MPS }\end{array}$ \\
\hline Processing delay & $50 \mathrm{~ns}$ & $10 \mathrm{~ns}$ \\
\hline Frequency bands & $\begin{array}{l}\text { Sub-6 GHz; } \\
\text { MmWave for fixed } \\
\text { access at } 26 \mathrm{GHz} \\
\text { and } 28 \mathrm{GHz} \text {. }\end{array}$ & $\begin{array}{l}\text { Sub- } 6 \mathrm{GHz} \text {; } \\
\text { MmWave for mobile } \\
\text { access; THz band } \\
\text { above } 300 \mathrm{GHz} \text {; Non } \\
\text { RF }\end{array}$ \\
\hline $\begin{array}{l}\text { Spectral and } \\
\text { energy efficiency } \\
\text { compared to } \\
\text { today's network }\end{array}$ & $\begin{array}{l}10 \text { up to } 100 \mathrm{x} \text { in } \\
\mathrm{bps} / \mathrm{Hz} / \mathrm{m}^{2} / \mathrm{Joules}\end{array}$ & $\begin{array}{l}1000 \mathrm{x} \text { in } \\
\mathrm{bps} / \mathrm{Hz} / \mathrm{m}^{3} / \mathrm{Joules} \\
\text { (volumetric) }\end{array}$ \\
\hline
\end{tabular}

Moreover, 6G network should provide support for greater number of massive machine type connected devices, than $5 \mathrm{G}$ network. In that direction 6G should provide scalability, efficient connectivity with connectivity and reliability, coverage improvement, as well as QoS and QoE provisioning. In order to manage such complex network, artificial intelligence (AI) with machine learning (ML) techniques are used to support the network autonomy, as well as to get a knowledge of the surrounding environment in with $6 \mathrm{G}$ network would operate. $6 \mathrm{G}$ network would possess self-healing, self-organization, self-reconfiguration, self-optimization, selfaggregation, and self-protection capabilities.

In addition, $6 \mathrm{G}$ is expected to make Internet of everything (IoE) to become reality, where billion of devices such as sensors, actuators, smartphones, tablets, vehicles, and many other objects would be connected to Internet and would generate a large amount of data [19]. Therefore, $6 \mathrm{G}$ network should be scalable, and coped with ML it will be able to analyze data, extract hidden knowledge, and to solve the issue of raw data transmission, as well as to improve the utilization of network resources.

$6 \mathrm{G}$ network and $6 \mathrm{G}$ devices would require much more energy than $5 \mathrm{G}$, since they would operate on higher frequency bands than $5 \mathrm{G}$. On other hand 6G network should have improved energy efficiency than $5 \mathrm{G}$ network. Therefore, at the moment new energy harvesting techniques are under investigation in order to resolve the issue with the $6 \mathrm{G}$ energy efficiency [20].

$6 \mathrm{G}$ users would be able to experience 3D holographic display [20]. In order to achieve this terrestrial and aerial devices should be employed.

In addition, 6G network would use telecommunication satellites, and earth imaging satellites to provide global coverage, localization services, broadcast and Internet connectivity. Finally, enhanced software-define networks (SDN) with network function virtualization (NFV) and network slicing would provide dynamic and programmatically efficient network management in 6G [20]. NFV would consolidate the network instruments onto the servers located at data centers, distributed network devices, or even at end-user premises. Dynamic network slicing allows a network operator to provide dedicated virtual networks in order to support optimal delivery of any service toward a wide range of users, machines, vehicles and industries. It is key management element when a large number of users are connected to a large number of heterogeneous networks in communication systems. 


\section{6G USE CASES}

There is continuous need for the revenue growth from the mobile operators' perspective [21]. However, this growth can be achieved only if it is possible to attract mobile users to mobile broadband. Therefore, mobile operators should provide support for new use cases of $6 \mathrm{G}$. This section highlights some of the potential $6 \mathrm{G}$ use cases.

One of the most critical application in 6G network is the holographic telepresence, which would enable users to enrich their traditional audiovisual communication with the sense of touch, while they are in different geographical locations [22]. 5G network would not be able completely to support holographic telepresence because it has very strict requirements such as terabits data rate (up to $4 \mathrm{~Tb} / \mathrm{s}$ ), ultra-low latency (less than $1 \mathrm{~ms}$ ), and reliable communications.

Another possibility for new revenue sources for larger growth of mobile sector is the digitalization of all segments of the public life, public administration and industry, which is expected to be achieved with the worldwide deployments of $5 \mathrm{G}$ network. This would enable telecom operators to include themselves into the new business models and value chain. The industrial automation, i.e. the digital transformation of traditional manufacturing and industrial processes via cyber-physical and IoT systems, also known as Industry 4.0 transform is expected to be completed with the deployment of $6 \mathrm{G}$ network, because some of these processes require high data rate, very low latency, jitter delay, etc. [23].

Smart environments, i.e. smart cities and smart homes tend significantly to increase the quality of life by performing optimization of the services and operations, resources management, automatization of the functions, etc. [20]. These services would be partially enabled by $5 \mathrm{G}$ network due to their strict requirements. $6 \mathrm{G}$ network is expected to complete task of smart environments.

With the technological innovations such as artificial intelligence, augmented reality, virtual reality, and holographic telepresence, $6 \mathrm{G}$ would offer many new possibilities in the e-health, since it would provide very high reliability $(99.99999 \%)$, very high precision, and very ultra-low latency $(<1$ ms) [20].

In addition, $6 \mathrm{G}$ network would provide a complete support of tactile internet, provide a more intelligent human-to-machine type of communication for real-time controlling IoT devices [24]. The tactile internet would enable humans and machines to exchange control, touch, and sense data in a realtime manner, which would provide support for haptics interface, as well as, possible visual feedback and remote response behavior that would be used in the industry, e-commerce, and many other possible applications.

Another potential use cases of $6 \mathrm{G}$ are the connected robots (robotic communications) and autonomous systems that would result with the usage of unmanned aerial vehicle (UAV) services in everyday life, industry and transportation [20]. Moreover, $6 \mathrm{G}$ network is expected to enable cellular vehicleto-anything (V2X) and vehicle-to-server connectivity in a very reliable fashion [25-26].

Augmented reality and virtual reality are the one of the most distinguished services being used in $5 \mathrm{G}$ networks. However, augmented and virtual reality would affect many research areas and provide new use cases, such as remote surgery, MMI, haptic technology, and game technology [27], may not be completely supported by $5 \mathrm{G}$ networks, because they may exceed the capacity of supported by $5 \mathrm{G}$ networks. Such new applications, are haptic technology and virtual meeting room (VMR) which would transmit a large amount of real-time data, and would require very low end-to-end latency. Therefore, $6 \mathrm{G}$ network is expected to accomplish these strict requirements for the future $\mathrm{AR}$ and VR applications.

\section{6G SERVICE CLASSES}

As it is already known, there are 3 main key service types introduced by 5G: Enhanced Mobile Broadband (eMBB), massive Machine Type Communication (mMTC) and Ultra-Reliable Low-Latency Communication (URLLC) [20]. Since 5G network would not satisfy many new upcoming applications and use cases, it is necessary to define new service classes in $6 \mathrm{G}$, which would provide extreme high data rates, extreme ultra low end-to-end latency, and very high reliability.

On the basis of the $6 \mathrm{G}$ use cases provided in the previous section, several new $6 \mathrm{G}$ service classes can be defined. In general, all service classes require low latency, high reliability, high data rate, massive connectivity, and full mobility. In [20] the following 6G service classes are defined: massive URLLC (mURLLC), enhanced mobile broadband URLLC (eURLLC), and massive eMBB (meMBB). 
The mURLLC is the 5G URLLC service class increased to a massive scale, and combines the URLLC with mMTC (mMTC + URLLC). One potential application in this class could be autonomous intelligent driving. The eURLLC service class combines both eMBB and URLLC classes (eMBB + URLLC). AR, VR and holographic meetings are some of the applications that fit into this service class. The meMBB service class combines the mMTC and eMBB classes (mMTC + eMBB). The tactile Internet fits into this class which would be used to improve the operations and functions in industrial IoT devices (IIoT) in Industry 4.0.

Apart from these 3 service classes in [16] and [28] are envisioned the following 6G service classes: Computation Oriented Communications (COC), Event Defined uRLLC (EDuRLLC), and Contextually Agile eMBB Communications $(\mathrm{CAeC})$. The COC would be able flexibly choose an operating point in the rate-latency-reliability space depending on the available communications resources in order to achieve a certain computational accuracy. The EDuRLLC would support uRLLC in extreme or emergency events with spatially and temporally changing device densities, traffic patterns, and spectrum and infrastructure availability. The $\mathrm{CAeC}$ should provide provision of eMBB services which would be adaptive to the network context (link congestion and network topology), physical environment (surrounding location and mobility) and social networking context (social neighborhood and sentiments).

In addition, the advances in industry and autonomous intelligent driving, as well as the potential convergence of photonics and artificial intelligence, would result with the appearance of new core service classes, such as ultra-High Speed with Low Latency Communications (uHSLLC), ultra-High Data Density (uHDD), and ubiquitous Mobile Ultra Broadband (uMUB) [29]. Also, Human Centric Services (HCS) and multi-purpose 3CLS (control localization and sensing) and energy services (MPS) have been introduced as new 6G service classes [17]. HCS services would require new Quality of Physical Experience (QoPE) metrical targets, tightly coupled with their users, rather than raw-reliability-latency QoS metrics. The multi-purpose 3CLS (control localization and sensing) and energy services would be particularly important for Connected Robots and Autonomous Systems (CRAS), which require joint uplink-downlink designs in order meet target performance for the control (e.g. stability), computing latency, target energy to transfer, localization precision, and accuracy of a mapped radio environment. This service class can also offer energy to small devices via wireless energy transfer.

\section{6G NETWORK ARCHITECTURE}

On the basis of the $6 \mathrm{G}$ network requirements and $6 \mathrm{G}$ use cases our proposed $6 \mathrm{G}$ network architecture is presented on Figure 2. It consists of different access networks such as air networks, ground networks, vehicle-to-vehicle communications, undersea networks, etc. connected to a single core with massive processing capacity capable to support cloud computing, network function virtualization (NFV) and software defined networking (SDN) [30]. The architecture of $6 \mathrm{G}$ network would consist of both: new technologies which would be invented by the evolution of the existing technologies, revolutionary technologies, and new revolutionary technologies.

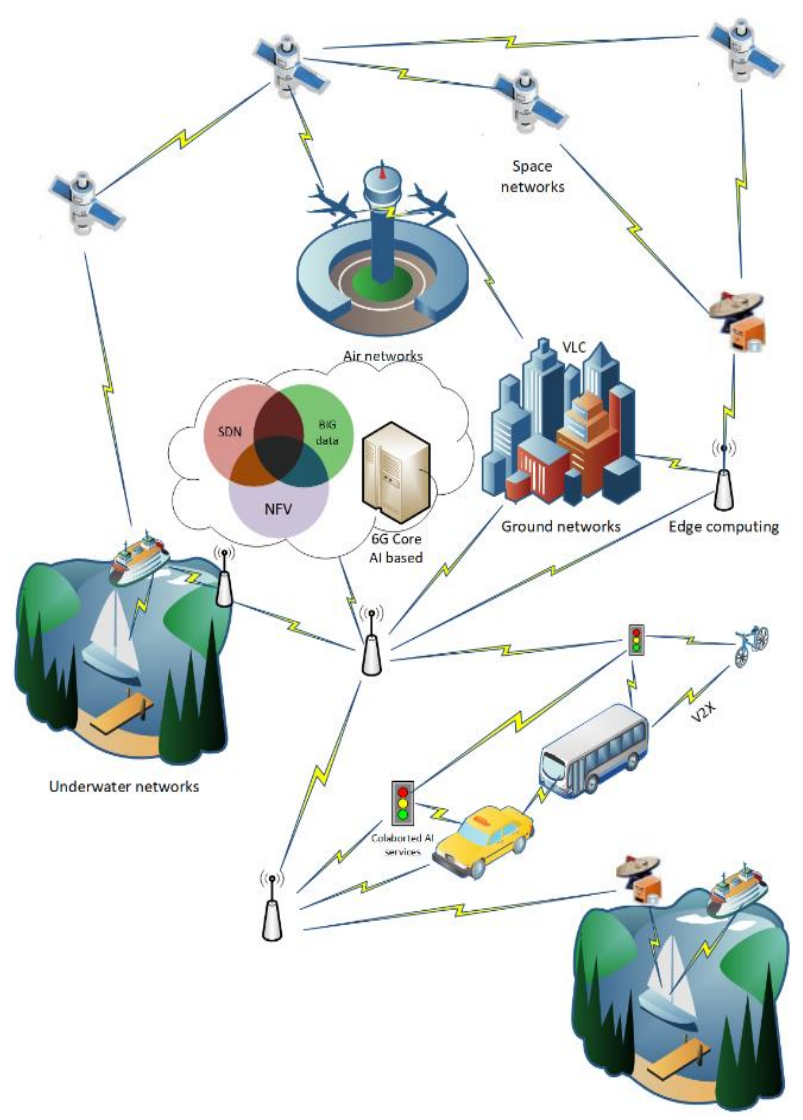

Fig. 2. 6G network architecture [30]

The evolutionary technologies are the following: non-terrestrial technologies (UAV and satellite communications), artificial intelligence, energy harvesting mechanisms, large intelligent surfaces 
(LIS), multi-access edge computing, non-orthogonal multiple access (NOMA), device-to-device (D2D) communication, grant-free transmission, sparse signal processing, and holographic MIMO surfaces.

UAV-assisted communications would be in 6G-enabled IoT networks, that can overcome geographical and environmental limitations on wireless communications such as ships on the ocean, deployed sensors in the remote / isolated regions, and out of terrestrial network coverage areas [31]. They can be incorporated into the cellular network as a new category of user equipment (UE) that gets services while it flies in the sky, or can work as aerial BSs or relay nodes to help legacy terrestrial wireless communications by connectivity from the sky. UAVs can provide more reliable connections, multi-user scheduling and better resource allocation for radio access.

Satellite communications that provide very high throughput would be integrated in $6 \mathrm{G}$ network in order to achieve ubiquitous connectivity, and broadband Internet connectivity, especially in the geographical regions that cannot be covered by the terrestrial communication networks. Furthermore, satellite communications can be utilized for IoT scenarios [32].

The most influential and recently proposed enabling technology for the $6 \mathrm{G}$ network is artificial intelligence (AI) [33]. In this network architecture $\mathrm{AI}$ is introduced at any horizontal or vertical level, at all TCP/IP layers, at any slice configuration and cloud-based network resource (edge computing). The result would be self-sustainable ultra-smart network that could offer advanced self-managed services.

6G design would introduce artificial intelligence (AI) analytics. Some proposals define descriptive, diagnostic, predictive and prescriptive data analytics [34-35]. Our scenario proposes following three AI data analytics types: network analytics that analyzes collected historical data to get insights of the network status especially of the PHY, MAC, network and transport layer, variety of QoS parameters and etc. Actually, it would provide network status and utilization opportunities. Work data which is obtained as an output of the network analytics processes would be used by Core data analytics for detecting and predicting the network anomalies in order to improve reliability and security of the network. The obtained data would be used to detect future faults based at historical and current information and network behavior. Resource alloca- tion solutions and notifications are expected to be output of this process. Predictive analytics would use data to forecast future resource availability based at user mobility prediction, traffic patterns and overload. It is expected optimized solutions to be proposed for allocation of the resources, network virtualization and slicing, edge computing, and optimization of virtual devices that consist the network in order to offer ultimate network utilization, data transfer speed and traffic QoS. In some points core and predictive analytics may overlap. Even if this scenario looks naive it isn't, it must consider a huge number of parameters, i.e., big data deep learning mechanisms which need to be optimized if end to end traffic optimization is used.

Energy harvesting mechanisms should be incorporated in order to meet strict energy limitations affordably and sustainably. These mechanisms can generate electrical power from the external sources for the energy supply of network devices, e.g., BSs and UEs. Two potential solutions have attracted increasing attention for tackling this issue, including 1) further improve the energy efficiency of lowpower devices, and 2) energy harvesting mechanisms and wireless information and power transfer (WIPT) [36]. The Terahertz (THz) communications and intelligent surfaces open up many opportunities to achieve the energy self-sufficiency and self-sustainability vision for the $6 \mathrm{G}$ network. For example, because of its better directionality, the $\mathrm{THz}$ frequency band is more efficient than lower frequency bands for WIPT scenarios.

Reconfigurable intelligent surfaces (RISs) and large intelligent surfaces (LISs) are smart electromagnetic materials that can be embedded in our environments, such as buildings, walls, and clothes. These surfaces able to change the reflection of radio waves and expected to lead to the introduction of new communication technologies such as holographic MIMO and holographic radio frequency (RF) [37]. Using LIS technology, massive MIMO systems' impressive performance gains can be reached and improve these systems' energy efficiency because LIS' elements do not dependent on any active power source to transmit data [38].

Multi-access Edge Computing (MEC) refers to the deployment and execution of distributed computing capabilities, content caching, and network data analytics and network decisions making at the network edge [39]. MEC would be a primary player in the $6 \mathrm{G}$ networks as it can act as an intermediate layer that allows active data analytics, where the 
data is generated. This paradigm is crucially essential for resource constrained services/applications [40]. In addition, MEC would rapidly reduce the end-to-end (E2E) latency by providing edge-based data processing and analytics approaches, for AR/VR and V2X services. Besides, MEC's localized data preprocessing capabilities can reduce the need for sending a considerable amount of redundant or unnecessary data to the cloud data centers. MEC is also expected to be used to efficiently manage network resources (e.g. computational and communication).

One of the most influential radio access mechanisms in 6G networks would be Non-Orthogonal Multiple Access (NOMA). It plays an important role in the implementation and optimization of polar coding and channel polarization methods. It also provides significant improvement in terms of security, secrecy capacity, and user fairness [41], by leveraging successive interference cancellation (SIC) technique and strong/weak users' decoding order. Massive URLLC is envisioned as one of the leading service classes in the $6 \mathrm{G}$ networks, where NOMA technologies have remarkable abilities in guaranteeing services such as mMTC and URLLC. Moreover, the MEC convergence with the NOMA, also called NOMA-assisted MEC, can further enhance the computation service in 6G [42].

Device-to-device (D2D) communication may provide $6 \mathrm{G}$ network infrastructure for various $\mathrm{D} 2 \mathrm{D}$ based solutions for NOMA, network slicing, and mobile edge computing (MEC) [11]. Furthermore, it is envisioned that low latency and high-speed D2D communication is essential for the $6 \mathrm{G}$ networks to deal with the limited distance communication because of $\mathrm{THz}$ technology in the future ultra-dense heterogeneous networks (UDHN).

Grant-free transmission technology [43] has been identified as a critical medium access control mechanism which would enable massive IoT connectivity over mobile networks. With this technology the devices can send their data during randomly chosen time-frequency resources in an automatic manner to realize low-latency access and decline signaling overhead associating with the scheduling request.

Sparse signal processing optimally utilizes sparsity in signals for reconstructing them efficiently and with fewer samples [44]. It can be used to accurately and effectively recognize active IoT devices in the grant-free transmission approach. Sparse signal processing is also important for realizing THz communications in the 6G networks. Due to THz channels' sparse nature, compressive sensing methods for sparse channel recovery in $\mathrm{THz}$ channels estimation can be used.

Holographic MIMO Surfaces (HMIMOS) is another $6 \mathrm{G}$ enabling technology which would improve massive MIMO technology in terms of size, cost, weight, and energy consumption by transforming the wireless network environment into a reconfigurable intelligent entity [45].

The revolutionary technologies in $6 \mathrm{G}$ networks are expected to be the following: Terahertz (THz) communications (millimeter waves communications), optical wireless technology, 3-dimensional (3D) network coverage, edge intelligence (EI), quantum communications, and cell-less or cell-free communication architecture.

Terahertz (THz) communications would be fundamental in 6G. The terahertz frequency band is between the mmWave and optical bands, and it ranges from $100 \mathrm{GHz}$ to $10 \mathrm{THz}$ [46]. THz frequency band is promised to provide data rates on hundreds of Gbps (e.g., $100 \mathrm{Gbps}$ ), secure transmissions, extensive connectivity, highly dense network, and enhance spectral efficiency, consequently increase the bandwidth $(>50 \mathrm{GHz})$ to meet the requirements of $6 \mathrm{G}$ use cases with massive data rates and ultra-low latency.

Optical Wireless Technology (OWC) would be used in $6 \mathrm{G}$, alongside radio frequency $(\mathrm{RF}) \mathrm{com}$ munications. OWC frequency range consists of infrared (IR), visible light communication (VLC), and ultraviolet (UV) spectrum [47]. Among OWC technologies, VLC is the most promising frequency spectrum because of the technology advancement and extensive using of light-emitting diodes (LEDs). The OWC in the visible spectrum (380 to 740 nanometers) is generally known as VLC, which visible to the human eye.

The maximum data rate of OWC is highly dependent on lighting technology. For example, a gallium nitride $(\mathrm{GaN})$-based LED can achieve data rate up to 4 Gbps [48 - 49]. The achievable data rate of VLC would reach hundreds of Gbps for the $6 \mathrm{G}$ network due to the technological improvements of LED lamps, as well as, the digital modulation techniques [50]. It is expected VLC technology to be widely used in different applications, such as intelligent transportation systems (ITSs), smart cities and homes, the advertising and entertainment industry, and hospitals.

$6 \mathrm{G}$ network would integrate the terrestrial and non-terrestrial technologies to support 3D network 
coverage [51]. Compared with the fixed 2D infrastructures, the $3 \mathrm{D}$ strategy is much more timely and economically efficient (telecommunications operators have to bear the cost of the deployment of dense mobile networks to guarantee massive connectivity), especially when the operators want to quickly provide seamless/reliable/continuous services in rural areas, or in the case of natural disasters. 3D coverage would also enable communication system for deep-sea and high altitude.

Edge Intelligence (EI) or edge AI is another promising computing paradigm that gains enormous interest [52 - 53]. Big data sources as an enabling technology for learning based solutions have recently represented a significant shift from the cloud data centers to the ever-increasing edge devices, e.g. smartphones and industrial IoT devices. It is evident that these edge devices would push the AI solutions to the edge of the network to exploit the edge big data sources' potential entirely.

$6 \mathrm{G}$ networks would adopt ubiquitous AI solutions from the network core to the edge devices. However, the conventional centralized ML algorithms need the availability of a large amount of centralized data and training on a central server (e.g., cloud server or centralized machine). This would result with a bottleneck in the future ultralarge scale mobile networks [54]. Fortunately, federated learning (FL) which is an emerging distributed ML technique, is a promising solution to deal with this challenge and realize ubiquitous $\mathrm{AI}$ in the $6 \mathrm{G}$ networks. FL does not rely on storing all data to a central server where model training can occur. Instead, the innovative idea of FL is to train an ML model at each device (participant or data owner) where data is generated, or a data source has resided, and then let the participants send their individual models to a server (or aggregation server) and like that to achieve an agreement for a global model. However, despite the considerable potential advantages of FL for the $6 \mathrm{G}$ networks, FL is still in its infancy and encounter various challenges for fully operationalize in the $6 \mathrm{G}$ networks.

Quantum communications has a strong potential to meet the stringent requirements of $6 \mathrm{G}$ such as massive data rates, efficient computing, and strong security [55]. In this direction, technologies such as quantum optical communications (QOCs), quantum optical twin, quantum communication, and quantum key distribution (QKD) have been investigated [56 - 57]. The main idea of QC-assisted communications is to use photons (or quantum fields) to encode the data in the quantum state (or qubits) and like that to transmit qubits from a quantum emitter to a quantum receiver. Qubits in communications bring enormous advantages, such as communication security, high-speed and low transmission losses in optical and radio mediums, lessening the chance of decoherence, etc. Moreover, QC-assisted communication shows excellent potentials for long-distance communications, where quantum repeaters can be used at long distances to divide the communication link into multiple shorter middle segments and then correct errors such as photon loss and operation errors in these segments [58]. In addition, AI would be revolutionized by $\mathrm{QC}$, because the existing $\mathrm{AI}$ techniques are quite expensive in terms of energy, time, and resources.

Cell-less communication architecture, also known as cell-free, has been proposed to deal with performance degradation poses by the cellular networks' handover process [59]. Under this architecture, a UE can communicate with cooperative BSs (or access points (APs)) through coordinated multipoint transmission and reception techniques instead of connecting to a single BS.

Cell-less communications enhance connectivity and lower the latency induced by the handover process. Cell-less communications would be inevitable in $6 \mathrm{G}$ networks because of the fast deployment of heterogeneous communication systems and using several frequency bands, where UEs would transfer from one network to another network without requiring doing handover process [25]. The UEs would be able to select the most optimal link from the available heterogeneous links (e.g., THz, mmWave, and VLC) in an automated manner. As a result, the issues of the traditional handover, such as data loss and handover delays/failures, can be alleviated and like a better QoS would be achieved. Cell-less communications would enable UEs' seamless mobility without overhead because of the handover process.

\section{6G USER THROUGHPUT}

The performances in $6 \mathrm{G}$ can be explored in many ways such as the user throughput. The following scenario is used. There is a region in which are located a group of $N$ smart user devices, which are covered either by $5 \mathrm{G}$ or $6 \mathrm{G}$ network. The user devices are assumed to be same smart capabilities capable, and are located on a different distance from the RANs. 
Throughput is the quantity of data that can pass from source to destination in a specific time. The user throughput $T$ can be calculated as a ratio of the peak data rate $R$, and the number of users $N$ :

$$
T=\frac{R}{N}
$$

The peak data rate for $5 \mathrm{G}$ and $6 \mathrm{G}$ network in downlink and uplink direction is given in Table 1. The number of the users is varied from 100 to 1000 . The user throughput results are shown in Figure 3. It can be noticed that $6 \mathrm{G}$ offers much higher user throughput than $5 \mathrm{G}$ in both downlink and uplink direction. This means that much higher quantity data can pass through $6 \mathrm{G}$ network rather than $5 \mathrm{G}$ network, since it offers user throughput in the order of Gbps, while 5G offers throughput in the order of Mbps.

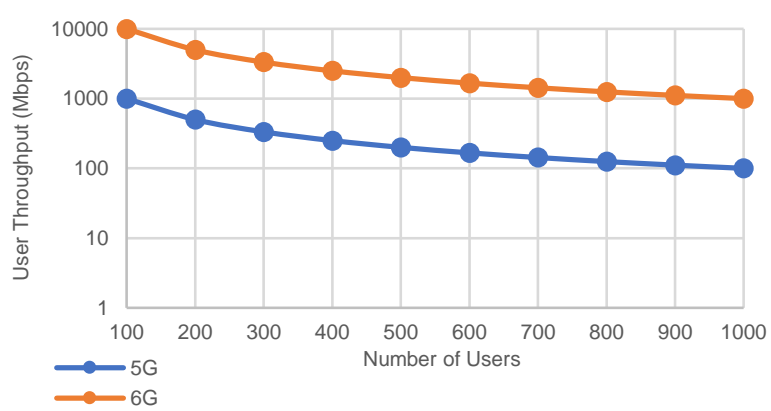

a) Ddownlink direction

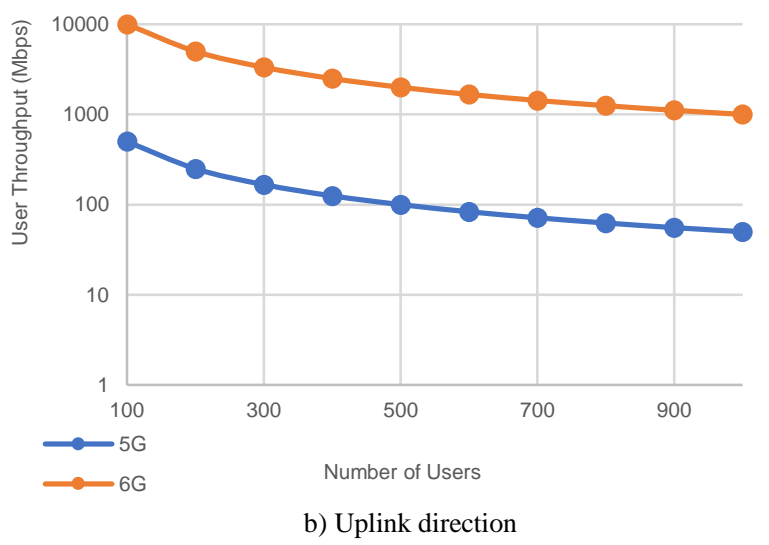

Fig. 3. A Comparison of the user throughput between $5 \mathrm{G}$ and $6 \mathrm{G}$ network architecture

\section{CONCLUSION}

The exponential increase in broadband multimedia wireless communications, as well as the rapid proliferation of smart mobile devices would shape the creation of the future 6th generation of mobile and wireless communications, also known as $6 \mathrm{G}$. Considering the network management and orchestration, signal processing and coding at the physical layer, manipulation of smart structures, and data mining of the network, service-based context-aware communications managed per device, we can conclude that AI will drive future end to end communication, including smart core, slices, smart edge network, CPE, any network terminal, phones and applications.

AI-enabled intelligent architecture of $6 \mathrm{G}$ networks will be implemented to realize knowledge discovery, smart resource management, automatic network adjustment and intelligent service provisioning. Collective AI represents advanced form of current AI techniques that address coexistence of multiple distributed mobile radio learning agents for variety of benefits. $6 \mathrm{G}$ deployment is expected to start around 2030. This network would be very much energy and bandwidth efficient.

New dimensions such as quantum communication, satellite integration and possible undersea wireless electromagnetic communication are expected to find place in 6G. In addition, terahertz, visible light communication and technologies, such as compressed sensing theory, new channel coding, large-scale antenna, flexible spectrum usage, AIbased wireless communication and special features as Space-Air-Ground-Sea integrated communication and wireless tactile network are few of the novelties that are expected to become a common network standard of $6 \mathrm{G}$.

Key $6 \mathrm{G}$ driver is expected to be the convergence of all past features as high throughput, network densification, low energy consumption, high reliability and massive connectivity. Future services would include AI, smart wearables, autonomous vehicles, computing reality devices, 3D mapping, sensing, augmented and virtual reality, holographic telepresence, Massive IoT Integrated Smart Cities, automation in manufacturing and many more. Selfevaluation at any level as availability effectiveness, security, efficiency, scalability, portability, flexibility will be driven by AI that will introduce the first self-sustain network.

\section{REFERENCES}

[1] Mumtaz, S., et al.: Terahertz Communication for Vehicular Networks, IEEE Transactions on Vehicular Technology, Vol. 66, No. 7, pp. 5617-5625, July 2017. 
[2] ITU-R M.2370-0: IMT Traffic Estimates for the Years 2020 to 2030, Jul. 2015.

[3] Nawaz, S. J., Sharma, S. K., Wyne, S., Patwary, M. N., Asaduzzaman, M.: Quantum machine learning for $6 \mathrm{G}$ communication networks: state-of-the-art and vision for the future, IEEE Access, Vol. 7, pp. 46317-46350 (2019).

[4] Clemm, A., Vega, M. T., Ravuri, H. K., Wauters, T., De Turck,: Toward truly immersive holographic-type communication: challenges and solutions, IEEE Communications Magazine, Vol. 58, No. 1, pp. 93-99, (Jan. 2020).

[5] Du, J., Jiang, C., Wang, J., Ren, Y., Debbah, M.: Machine learning for $6 \mathrm{G}$ wireless networks: Carrying forward enhanced bandwidth, massive access, and ultrareliable / low-latency service, IEEE Vehicular Technology Magazine, Vol. 15, No. 4, pp. 122-134 (Sep. 2020).

[6] Strinati, E. C., Barbarossa, S., Gonzalez-Jimenez, J. L., Ktenas, D., Cassiau, N., Maret, L., Dehos, C.: 6G: The next frontier: From holographic messaging to artificial intelligence using subterahertz and visible light communication, IEEE Vehicular Technology Magazine, Vol. 14, No. 3, pp. 42-50 (Aug. 2019).

[7] Jiang, D., Liu, G.: An overview of $5 \mathrm{G}$ requirements. In: $5 G$ Mobile Communications. Springer, Oct. 2017, pp. $3-$ 26.

[8] Swarna Priya R. M. Sweta Bhattacharya, Praveen Kumar Reddy Maddikunta, Siva Rama Krishnan Somayaji, Kuruva Lakshmanna, Rajesh Kaluri, Aseel Hussien, Thippa Reddy Gadekallu: Load balancing of energy cloud using wind driven and firefly algorithms in internet of everything, Journal of Parallel and Distributed Computing, Vol. 142, pp 16-26 (Aug. 2020).

[9] Zhang, L., Liang, Y.-C., Niyato, D.: 6G visions: Mobile ultrabroadband, super internet-of-things, and artificial intelligence, China Communications, Vol. 16, No. 8, pp. 1-14 (Aug. 2019).

[10] Nayak, S., Patgiri, R.: 6G: Envisioning the key issues and challenges, arXiv preprint arXiv: 2004.04024, Jun. 2020.

[11] Zhang, S., Liu, J., Guo, H., Qi. M., Kato, N.: Envisioning device to-device communications in 6G, IEEE Network, Vol. 34, No. 3, pp. 86-91 (March 2020).

[12] Tang, F., Kawamoto, Y., Kato, N., Liu, J.: Future intelligent and secure vehicular network toward 6G: Machinelearning approaches, Proceedings of the IEEE, Vol. 108, No. 2, pp. 292-307 (Dec. 2019).

[13] Gupta, R., Shukla, A., Tanwar, S.: BATS: A blockchain and AI-empowered drone-assisted telesurgery system towards 6G, IEEE Transactions on Network Science and Engineering, Dec. 2020.

[14] Khan, L. U., Yaqoob, I., Imran, M., Han, Z., Hong, C. S.: $6 \mathrm{G}$ wireless systems: A vision, architectural elements, and future directions, IEEE Access, Vol. 8, pp. 147 029-147 044 (Aug. 2020).

[15] Lv, Z., Qiao, L., You, I.: 6G-enabled network in box for internet of connected vehicles, IEEE Transactions on Intelligent Transportation Systems, Nov. 2020.

[16] Letaief, K. B., Chen, W., Shi, Y., Zhang, J., Zhang, Y. A.: The Roadmap to 6G: AI empowered wireless networks, IEEE Communications Magazine, Vol. 57, No. 8 (August, 2019).

[17] W. Saad, M. Bennis, and M. Chen: A vision of $6 \mathrm{G}$ wireless systems: applications, trends, technologies, and open research problems: IEEE Network, Vol. 34, No. 8, pp. 134 142,2020
[18] Sliwa, B., Falkenberg, R., Wietfeld. C.: Towards cooperative data rate prediction for future mobile and vehicular $6 \mathrm{G}$ networks, Proc. $6 G$ Wireless Summit (6G SUMMIT), Levi, Finland, Mar. 2020, pp. 1-5.

[19] CISCO: The Internet of Everything, https://www.cisco.com/c/dam/en_us/about/business-insig hts/docs/ioe-value-at-stake-public-sector-analysis-faq.pdf. [Online available, accessed on Dec. 25, 2021].

[20] Shahraki, A., Abbasi, M., Piran, Md. J., Chen, M., Chui, S.: A comprehensive survey of $6 \mathrm{G}$ networks: applications, core services, enabling technologies, and future challenges, Internet of Things Journal, Vol. XX, No. XX (2020).

[21] Petrov, I., Janevski, T.: 5G technologies and business aspects: high-level point of view, Journal of Electrical Engineering and Information Technologies, Vol. 5, No. 1, pp. 61-68 (2020).

[22] Clemm, A., Vega, M. T., Ravuri, H. K., Wauters, T., De Turck, F.: Toward truly immersive holographic-type communication: challenges and solutions, IEEE Соттиnications Magazine, Vol. 58, No. 1, pp. 93-99 (Jan. 2020).

[23] Berardinelli, G., Mahmood, N. H., Rodriguez, I., Mogensen, P.: Beyond 5G wireless IRT for industry 4.0: Design principles and spectrum aspects, Proc. IEEE Global Communications Conference Workshops (GC Wkshps), Abu Dhabi, United Arab Emirates, Dec. 2018, pp. 1-6.

[24] Lu, Y., Zheng, X.: 6G: A survey on technologies, scenarios, challenges, and the related issues, Journal of Industrial Information Integration, Vol. 19, p. 100158 (Jul. 2020).

[25] Chowdhury, M. Z., Shahjalal, M., Ahmed, S., Jang, Y. M.: $6 \mathrm{G}$ wireless communication systems: Applications, requirements, technologies, challenges, and research directions, IEEE Open Journal of the Communications Society, Vol. 1, pp. 957-975 (Jul. 2020).

[26] Deebak, B., Al-Turjman, F.: Drone of IoT in 6G wireless communications: technology, challenges, and future aspects, Unmanned Aerial Vehicles in Smart Cities. Springer, April. 2020, pp. 153-165.

[27] Van Den Berg, D., Glans, R., De Koning, D., Kuipers, F. A., Lugtenburg, J., Polachan, K., Venkata, P. T., Singh, C., Turkovic, B., Van Wijk, B.: Challenges in haptic communications over the tactile internet, IEEE Access, Vol. 5, pp. 23 502-23 518 (Oct. 2017).

[28] Sergiou, C., Lestas, M., Antoniou, P., Liaskos, C., Pitsillides, A.: Complex systems: A communication networks perspective towards 6G, IEEE Access, Vol. 8, pp. 89007 89030 (May 2020).

[29] Zong, B., Fan, C., Wang, X., Duan, X., Wang, B., Wang, J.: 6G technologies: Key drivers, core requirements, system architectures, and enabling technologies, IEEE Vehicular Technology Magazine, Vol. 14, No. 3, pp. 18-27 (Jul. 2019)

[30] Petrov, I., Janevski, T., Kitanov, S.: An overview of 6G mobile networks with artificial intelligence towards sustainable development, South East European Journal of Sustainable Development, Vol. 5, No. 2, Skopje, Macedonia, 2021.

[31] Chen, M., Mozaffari, M., Saad, W., Yin, C., Debbah, M., Hong, C. S.: Caching in the sky: Proactive deployment of cache-enabled unmanned aerial vehicles for optimized quality-of-experience, IEEE Journal on Selected Areas in Communications, Vol. 35, No. 5, pp. 1046-1061 (Mar. 2017). 
[32] Routray, S. K., Hussein, H. M.: Satellite based IoT networks for emerging applications, arXiv preprint arXiv: 1904.00520 (Mar 2019).

[33] Chen, M., Challita, U., Saad, W., Yin, C., Debbah, M.: Artificial neural networks-based machine learning for wireless networks: A tutorial, IEEE Communications Surveys \& Tutorials, Vol. 21, No. 4, pp. 3039-3071 (Jul. 2019).

[34] Balali, F., Nouri, J., Nasiri, A., Zhao, T.: Data analytics. In: Data Intensive Industrial Asset Management, Springer, 2020, pp. 105-113.

[35] Kibria, M. G., Nguyen, K., Villardi, G. P., Zhao, O., Ishizu, K., Kojima, F.: Big data analytics, machine learning, and artificial intelligence in next-generation wireless networks, IEEE Access, Vol. 6, pp. 32 328-32 338 (May 2018).

[36] Ng, D. W. K., Duong, T. Q., Zhong, C., Schober, R.: Wireless Information and Power Transfer: Theory and Practice. John Wiley \& Sons, Jan 2019.

[37] Di Renzo, M., Zappone, A., Debbah, M., Alouini, M.-S., Yuen, C., De Rosny, J., Tretyakov, S.: Smart radio environments empowered by reconfigurable intelligent surfaces: How it works, state of research, and road ahead, arXiv preprint arXiv:2004.09352, Apr 2020.

[38] Yuan, Y., Zhao, Y., Zong, B., Parolari, S.: Potential key technologies for $6 \mathrm{G}$ mobile communications, Science China Information Sciences, Vol. 63, pp. 1-19 (Aug. 2020).

[39] Taleb, T., Samdanis, K., Mada, B., Flinck, H., Dutta, S., Sabella, D.: On multi-access edge computing: A survey of the emerging $5 \mathrm{G}$ network edge cloud architecture and orchestration, IEEE Communications Surveys \& Tutorials, Vol. 19, No. 3, pp. 1657-1681 (May 2017).

[40] Mahmood, N. H., Alves, H., L'opez, O. A., Shehab, M., Osorio, D. P. M., Latva-aho, M.: Six key enablers for machine type communication in 6G, arXiv preprint arXiv:1903.05406, Mar. 2019.

[41] Khan. W. U., Jameel, F., Ristaniemi, T., Khan, S., Sidhu, G. A. S., and Liu, J.: Joint spectral and energy efficiency optimization for downlink NOMA networks, IEEE Transactions on Cognitive Communications and Networking, Vol. 6, No. 2, pp. 645-656 (Oct. 2020).

[42] Li, H., Fang, F., Ding, Z.: Joint resource allocation for hybrid NOMA-assisted MEC in 6G networks, Digital Communications and Networks, Vol. 6, No. 3, pp. 241-252 (Aug. 2020)

[43] Bi, Q.: Ten trends in the cellular industry and an outlook on 6G, IEEE Communications Magazine, Vol. 57, No. 12, pp. 31-36 (Dec. 2019).

[44] Liu, L., Larsson, E. G., Yu, W., Popovski, P., Stefanovic, C., De Carvalho, E.: Sparse signal processing for grantfree massive connectivity: A future paradigm for random access protocols in the Internet of Things, IEEE Signal Processing Magazine, Vol. 35, No. 5, pp. 88-99 (Sep. 2018).

[45] Huang, C., Hu, S., Alexandropoulos, G. C., Zappone, A., Yuen, C., Zhang, R., Renzo, M. D., Debbah, M.: Holographic MIMO surfaces for $6 \mathrm{G}$ wireless networks: Opportunities, challenges, and trends, IEEE Wireless Communications, Vol. 27, No. 5, pp. 118-125 (Jul. 2020).
[46] Jornet, J. M., Akyildiz, I. F.: Channel modeling and capacity analysis for electromagnetic wireless nanonetworks in the terahertz band, IEEE Transactions on Wireless Communications, Vol. 10, No. 10, pp. 3211-3221 (Aug. 2011).

[47] Chowdhury, M. Z., Hossan, M. T., Islam, A., Jang, Y. M.: A comparative survey of optical wireless technologies: Architectures and applications, IEEE Access, Vol. 6, pp. 9819-9840 (Jan. 2018).

[48] Lee, C., Zhang, C., Cantore, M., Farrell, R. M., Oh, S. H., Margalith, T., Speck, J. S., Nakamura, S., Bowers, J. E., DenBaars, S. P.: 4 Gbps direct modulation of $450 \mathrm{~nm} \mathrm{GaN}$ laser for high-speed visible light communication, Optics Express, Vol. 23, No. 12, pp. 16 232-16 237 (Jun. 2015).

[49] Tsonev, D., Chun, H., Rajbhandari, S., McKendry, J. J., Videv, S., Gu, E., Haji, M., Watson, S., Kelly, A. E., Faulkner, G., et al.: A 3-Gb/s single-LED OFDM-based wireless VLC link using a gallium nitride, IEEE Photonics Technology Letters, Vol. 26, No. 7, pp. 637-640 (Jan. 2014).

[50] Viola, S., Islim, M. S., Watson, S., Videv, S., Haas, H., Kelly, A. E.: $15 \mathrm{~Gb} / \mathrm{s}$ OFDM-based VLC using direct modulation of $450 \mathrm{GaN}$ laser diode. In: Advanced FreeSpace Optical Communication Techniques and Applications III, Vol. 10437. International Society for Optics and Photonics, Oct. 2017, p. 104370E.

[51] Giordani. M., Polese, M., Mezzavilla, M., Rangan, S., and Zorzi, M.: Toward 6G networks: Use cases and technologies, IEEE Communications Magazine, Vol. 58, No. 3, pp. 55-61, Mar. 2020.

[52] Chen, M., Yang, Z., Saad, W., Yin, C., Poor, H. V., and Cui, S.: A joint learning and communications framework for federated learning over wireless networks. IEEE Transactions on Wireless Communications, to appear, 2020.

[53] Chen, M., Poor, H. V., Saad, W., Cui, S.: Wireless communications for collaborative federated learning, arXiv preprint arXiv:2006.02499, Jun. 2020.

[54] Lu, Y., Huang, X., Zhang, K., Maharjan, S., Zhang, Y.: Low-latency federated learning and blockchain for edge association in digital twin empowered $6 \mathrm{G}$ networks, IEEE Transactions on Industrial Informatics, pp. 1-1 (Aug. 2020).

[55] Gyongyosi, L., Imre, S.: A survey on quantum computing technology, Computer Science Review, Vol. 31, pp. 51-71 (Feb. 2019).

[56] Manzalini, A.: Quantum communications in future networks and services," Quantum Reports, Vol. 2, No. 1, pp. 221-232 (Mar. 2020).

[57] M. M. Wilde and M.-H. Hsieh, "The quantum dynamic capacity formula of a quantum channel, Quantum Information Processing, Vol. 11, No. 6, pp. 1431-1463 (Dec. 2012).

[58] Ruihong, Q., Ying, M.: Research progress of quantum repeaters, Vol. 1237, No. 5, pp. 052 032-052 039 (Jun. 2019).

[59] Wang, L., Han, T., Li, Q., Yan, J., Liu, X., Deng, D.: Cellless communications in $5 \mathrm{G}$ vehicular networks based on vehicle-installed access points, IEEE Wireless Communications, Vol. 24, No. 6, pp. 64-71 (Dec. 2017). 
